\title{
Transcriptome analysis of cervical cancer exosomes and detection of HPVE6*I transcripts in exosomal RNA
}

\author{
Anjali Bhat', Joni Yadav', Kulbhushan Thakur', Nikita Aggarwal' ', Arun Chhokarr', Tanya Tripathi', Tejveer Singh',
} Mohit Jadli ${ }^{1}$, Veeramohan Veerapandian ${ }^{2}$ and Alok Chandra Bharti ${ }^{*}$

\begin{abstract}
Background: Exosomes play a key role in cell-to-cell communication and are integral component of the tumor microenvironment. Recent observations suggest transfer of RNA through tumor-derived exosomes that can potentially translate into regulatory proteins in the recipient cells. Role of cervical cancer-derived exosomes and their transcript cargo is poorly understood.
\end{abstract}

Materials and methods: The total RNA of exosomes from HPV-positive (SiHa and HeLa) and HPV-negative (C33a) cervical cancer cell lines were extracted and the transcripts were estimated using Illumina HiSeq X. Further, validation of HPV transcripts were performed using RT-PCR.

Results: 3099 transcripts were found to be differentially-exported in HPV-positive vs. HPV-negative exosomes ( $p$ value $<0.05$ ). Analysis of top $10 \mathrm{GO}$ terms and KEGG pathways showed enrichment of transcripts belonging to axon guidance and tumor innervation in HPV-positive exosomes. Among top 20 overexpressed transcripts, EVC2, LUZP1 and ANKS1B were the most notable due to their involvement in Hh signaling, cellular migration and invasion, respectively. Further, low levels of HPV-specific reads were detected. RT-PCR validation revealed presence of E6*I splice variant of HPV18 in exosomal RNA of HeLa cells. The E6*I transcripts were consistently retained in exosomes obtained from HeLa cells undergoing 5-FU and cisplatin-induced oxidative stress.

Conclusion: Our data suggests the enrichment of poly-A RNA transcripts in the exosomal cargo of cervical cancer cells, which includes pro-tumorigenic cellular RNA and viral transcripts such as HPV E6, which may have clinical utility as potential exosomal biomarkers of cervical cancer.

Keywords: Cervical cancer, Exosome, Human papillomavirus, Next generation sequencing, Transcript profiling, Reverse transcriptase polymerase chain reaction, Oncoprotein E6

\section{Background}

Cervical cancer is a disease caused by persistent infection of high-risk Human Papillomavirus (HPV). Despite being a preventable cancer with available clinically-proven

\footnotetext{
*Correspondence: alokchandrab@yahoo.com

${ }^{1}$ Molecular Oncology Laboratory, Department of Zoology, University

of Delhi (North Campus), Delhi 110007, India

Full list of author information is available at the end of the article
}

prevention tools [1], the disease remains a significant health challenge to women with poor socioeconomic status and is often detected in late stages [2]. Exosomes play an important role in intercellular communication [3]. Tumor-derived exosomes have emerged as mediators of cancer initiation, tumor promotion, metastastic spread, enhanced angiogenesis and drug resistance in a variety of cancers by conditioning the stromal cells and the tumor microenvironment $[4,5]$. Therefore, for better 
understanding of tumor progression, improved exosome based diagnostic and prognostic tools can be developed for effective control and management of cervical cancer. Evidence accumulated over last decade has revealed a strong pro-tumorigenic role of exosomes in cervical cancer. However, role of tumor-derived exosomes and its cargo needs detailed exploration.

Cervical cancer exosomes are known to regulate metastasis $[6,7]$, angiogenesis $[8,9]$, drug resistance $[10$, 11] and tumor progression [12]. Though all three major classes of macromolecules namely DNA, RNA and proteins have been reported in tumor exosomes, the expression of the constituent molecules may greatly differ in comparison to their cell of origin suggestive of selective packaging [13]. Presence of nucleic acids in exosomal cargo is intriguing due to its longer and stronger impact on target cells and is confirmed to be intra-luminal cargo but not an exosome isolation artefact [14]. Multiple RNA types are packaged into the exosomal RNA pool, which include selected portion of the source cell's RNA spectrum [15]. Small non-coding RNAs are the dominant molecules of the exosomal RNA cargo [7-10, 12]. Similarly, a differential exosomal export of lncRNAs HOTAIR, MALAT1, and MEG3 levels in cervico-lavage samples correlated with cervical cancer progression [16]. Cervical cancer exosomes carried competing endogenous RNA HNF1A-AS1 of miR-34b and promoted cisplatin resistance [11]. Collectively, these molecules have profound effect on the functions of cells that take up the exosomes.

Apart from the regulatory and ribosomal RNA, accumulating evidence highlight the presence of mRNA in exosomal cargo of normal $[17,18]$, transformed [19] and some cancer cells [14, 20-22]. Although the constitution and biological relevance of this RNA class is poorly defined, the transcripts are hypothesized to participate in horizontal transfer of genetic information as the exosomal mRNA could serve as ready to use templates for de novo protein synthesis in the recipient cells [23]. In view of miRNAs' low quantities and lack of target specificity, functional mRNA may play an equal or perhaps an even more significant role in cell-cell communication by complementing biological signaling pathways, and thus contributing to the disease progression. However, a comprehensive analysis of exosomal mRNA cargo in the cervical cancer cells is currently lacking.

HPV drives cervical carcinogenesis through expression of its viral oncogene E6 and E7 [24] that are coded by a short segment of DNA <1000bp. These genes have an independent transforming potential in cervical epithelial cells [25]. HPV E6/E7 oncogenes have been shown to influence both the content and amount of extracellular vesicles released from HPV positive cells $[26,27]$. In an experimental system using keratinocytes transduced with HPV16 E6 and E7 genes, exosomal export of E6 and E7 transcripts was noted that got transferred to non-infected keratinocytes [28]. Therefore, the study of HPV transcripts in exosomal compartment in cervical cancer needs further exploration. In the present study, we screened HPV-negative and HPV-positive cervical cancer exosomes for differentially exported cellular and viral transcripts using NGS analysis.

\section{Materials and methods \\ Materials}

Human cervical cancer cell lines with known HPV positivity for HPV type 16 - SiHa, HPV type 18 - HeLa; and HPV-negative C33a were originally procured from ATCC. The materials used in the study have been listed along with their source of procurement. The materials used in the study have been listed along with their source of procurement. DMEM (\#AL111-18X500ML), MEM (\#AT154), antibiotic solutions (\#A018), bovine serum albumin fraction V (\#RM10409) were procured from HiMedia Laboratories Pvt. Ltd. (Mumbai, India), Pierce $^{\mathrm{TM}}$ BCA Protein Assay Kit (\#23225), exosomedepleted serum One Shot ${ }^{\text {TM }}$ format (\#A2720803), Precision Plus Protein Dual Color Standards from Bio-Rad, USA (\#161-0374), High-Capacity cDNA Reverse Transcription Kit (Applied Biosystems ${ }^{\mathrm{TM}}$; \#4368814), TRIzol RNA Isolation Reagent (\#AM9738) were procured from Thermo Fischer Scientific (Waltham, USA). ExoEnrich $^{\mathrm{TM}}$ (\#PEC-50), ExoLyseP ${ }^{\mathrm{TM}}$ (\#PEL-25P) were purchased from ExoCan Healthcare Technologies Ltd. (Pune, India). ECL-substrate (\#SC-2048) from Santa Cruz Biotechnology, Inc. (Dallas, USA). All the antibodies were procured from Santacruz Biotechnology, Inc. (USA) and Sigma (St. Louis, USA) (Supplementary Table 1) and oligos used in the study were procured from Eurofins scientific (Supplementary Table 2). Millipore PVDF membrane (\#HVLP04700), RNAse A (\#P4170), and all other reagents unless specified were procured from Sigma.

\section{Preparation of cell culture conditioned media for exosome studies}

Briefly, cells were seeded at $25 \%$ confluency $\left(9 \times 10^{5}\right)$ in a $100 \mathrm{~mm}$ culture plate containing $10 \%$ exosome depletedFBS and allowed to grow for 4 days. After 4 days, cell culture conditioned medium containing exosomes was harvested and centrifuged at $5000 \mathrm{rpm}$ for $30 \mathrm{~min}$ to pellet down remaining cellular debris. The resulting supernatant was then subjected to $0.2 \mu \mathrm{m}$ filtration step using $0.22 \mu \mathrm{m}$ membrane (Millipore, MA, USA). 
Isolation of exosomes from cervical cell culture conditioned medium

Exosomes were isolated using commercially available kit, ExoEnrich $^{\mathrm{TM}}$ as described previously without any deviation Exosomes were isolated using ExoEnrich ${ }^{\mathrm{TM}}$ (PEC-50; ExoCan Healthcare Technologies Ltd, Pune, India) as per manufacturer's instructions [29]. Briefly, $4 \mathrm{ml}$ of culture conditioned medium was mixed with $100 \mu \mathrm{l}$ of solution A followed by addition of $2 \mathrm{ml}$ of solution $\mathrm{B}$. The resulting suspension was mixed by gentle pipetting and centrifuged at $3000 \mathrm{rpm}$ for $20 \mathrm{~min}$. The exosome pellet was washed with $1 \times$ PBS twice at $3000 \mathrm{rpm}, 3$ times each. The exosomes were used in downstream analysis or were stored at $-20^{\circ} \mathrm{C}$ until further use.

\section{Transmission electron microscopy (TEM) of cervical cancer exosomes}

TEM analysis of exosome samples was performed according to previously published reports with minor modifications [30, 31]. Freshly isolated cervical cancer exosomes were resuspended in $30 \mu \mathrm{l}$ of $1 \mathrm{X}$ PBS containing $2 \%$ paraformaldehyde. Exosomes were prepared for TEM inspection by adsorbing onto Formvar carbon-coated nickel grid for a time period of $1 \mathrm{~h}$. The grids were fixed by $2.5 \%$ glutaraldehyde in $0.1 \mathrm{M}$ sodium cacodylate, $\mathrm{pH}$ 7.6 for $10 \mathrm{~min}$. After rinsing with sterile distilled water, the grids were contrasted using uranyl-oxalate solution at $\mathrm{pH} 7$ for $5 \mathrm{~min}$, air-dried for $5 \mathrm{~min}$ and examined with a JEOL 2100F transmission electron microscope (JEOL Ltd., Tokyo, Japan) operated at $100 \mathrm{kV}$.

\section{Isolation of exosomal proteins and immunoblotting for exosome-specific markers}

Total exosome proteins were isolated using ExoLyseP ${ }^{\mathrm{TM}}$ and immunoblotted as described earlier [29]. Antibodies and their specific dilution in the blocking solution used in the study are described in Supplementary Table 1. Immuno-active bands were detected on an Amersham Imager 600 (GE Life Sciences ABI, Sweden) after 5 min treatment of the blot with enhanced chemiluminescence detection kit.

\section{Cellular and exosomal RNA isolation and quantification}

Exosome pellets were removed of exterior DNA by DNaseI digestion and treated with RNase to remove outer RNA as using TRIzol reagent as per manufacturer's instructions. Trizol was added to $10^{6}$ cells and to exosomes isolated from $4 \mathrm{ml}$ of conditioned medium normalized per $10^{6}$ cells from all the cell lines followed by homogenization and treatment of chloroform. The suspension was allowed to stand at RT for five minutes and then subjected to centrifugation at 12,000 rpm for 15 minutes as per manufacturer's instructions. The aqueous layer was taken off and collected in a new tube. RNA was precipitated using isopropanol at $-80^{\circ} \mathrm{C}$ for overnight and pelleted at 12,000 rpm for $20 \mathrm{~min}$. Isolated RNA was dissolved in a minimum of $20 \mu \mathrm{l}$ of nuclease free water. RNA was quantified spectrophotometrically using NanoQuant $\mathrm{T}^{\mathrm{m}}$ (Tecan). For RNA visualization silver staining was performed on non-denaturing PAGE as described earlier [29]. Briefly, RNA was isolated from exosome preparations (from $4 \mathrm{ml}$ culture conditioned medium) and subjected to polyacrylamide gel electrophoresis for $3 \mathrm{~h}$ at $100 \mathrm{~V}$ in $0.5 \times$ Tris-borate buffer. The gel was fixed in 150 $\mathrm{ml}$ of 50\% Methanol 5\% Acetic acid for $20 \mathrm{~min}$ followed by washing with $50 \%$ Methanol and water for $10 \mathrm{~min}$. The gel was sensitized using $0.02 \%$ sodium thiosulphate solution for $1 \mathrm{~min}$ followed by a silver reaction using $0.1 \%$ Silver Nitrate in $0.08 \%$ formalin (37\%) for $20 \mathrm{~min}$ and developed using $2 \%$ sodium carbonate with $0.04 \%$ formalin. The RNA concentrations were determined by Qubit (Thermo Fisher Scientific, USA) and the RIN for sequencing analysis.

\section{Transcript analysis by reverse transcriptase (RT)-PCR}

A minimum of $2 \mu \mathrm{g}$ of sample RNA was used for cDNA synthesis in a $20 \mu \mathrm{l}$ reaction using High-Capacity cDNA Synthesis Kit as described previously [32]. PCR was performed for amplification of specific genes on Veriti Thermal Cycler Pro from Applied Biosystems in a $10 \mu \mathrm{l}$ reaction volume. Primer sequence with annealing temperature is described in Supplementary Table ST2.

Modulation of exosomal HPV RNA cargo by cytotoxic drugs HPV-positive cervical cancer cells were exposed to cytotoxic drugs, 5-FU and cisplatin. For this, $2.5 \times 10^{3}$ cells were seeded in a 96-well plate and grown overnight to allow attachment. Subsequently, cells were treated with $\mathrm{IC}_{50}$ doses of 5-FU (17.58 $\mu \mathrm{M}$ : SiHa; $15.31 \mu \mathrm{M}$ : HeLa) and cisplatin (24.14 $\mu \mathrm{M}$ : SiHa; $6.82 \mu \mathrm{M}$ : HeLa) for $48 \mathrm{~h}$ and the exosomes were isolated from the conditioned media of treated cells. The exosomal RNA was isolated and examined for modulation of HPV transcripts by typespecific HPVE6 and E7 RT-PCR.

\section{RNA isolation, NGS library preparation and sequencing}

RNA isolation, NGS library preparation and highthroughput sequencing was outsourced to Clevergene Biocorp. Pvt Ltd. (Bengaluru, Karnataka, India). Total RNA in the exosomes was isolated using the TRIzol reagent according to the manufacturer's instructions. The RNA concentrations were determined by Qubit (Thermo Fisher Scientific, USA) and the RIN (RNA Integrity Number) was checked by Agilent 2100 Bioanalyzer (Agilent Technologies). For each library preparation, $1 \mathrm{ng}$ of 
total RNA from each sample was used. NEBNext Ultra II RNA Library Prep Kit for Illumina (\# E7775) was used. Total cDNA was ligated with P7 and P5 adapter sets. The PCR products were gel purified and their quality confirmed by Bioanalyzer (Supplementary Fig. SF1). Pairedend sequencing was performed on these libraries using an Illumina HiSeq X platform with a minimum of 25-30 million reads per sample.

\section{Sequence data QC}

NGS data quality was checked using FastQC (http:// www.bioinformatics.babraham.ac.uk/projects/fastqc/) and MultiQC [33]. The data was checked for base call quality distribution, \% bases above Q20, Q30, \%GC, and sequencing adapter contamination (Supplementary Table ST3). Raw sequence reads were processed to remove adapter sequences and low-quality bases using fastp [34].

\section{Alignment and expression analysis}

The QC passed reads were mapped onto indexed Human (GRCh38.p7), HPV16 and HPV18 reference genome using STAR v2 aligner [35]. Uniquely mapped reads were used for transcripts assembly. For assembling transcripts, StringTie was used with default parameters [36]. Assembled transcripts of all the samples were merged into a single gtf file using the String Tie merge option. The merged gtf was compared and annotated with reference gff using gff compare [37]. The relationship between the assembled transcripts and closely related reference transcripts along with the key for these codes is provided in Supplementary Fig. SF2.

\section{Differential transcript abundance analysis}

Differential analysis was carried out using the DESeq2 [38]. The read counts were normalized (variance stabilized normalized counts) and differential enrichment analysis was performed. For HPV-negative vs. HPV-positive analysis, C33a was used as reference and $\mathrm{SiHa}$ and HeLa exosomal transcripts were used as test groups. For HPV16 vs. HPV18 analysis, SiHa was used as reference and HeLa exosomal transcripts were used as test group. Transcripts with absolute log2 fold change $\geq 1.5$ and p-value $\leq 0.05$ were considered significant. The profile of differentially exported transcripts across the samples was evaluated using volcano plots. The transcripts that showed significant differential expression for human reference genome (GRCh38.p7) were used for Gene Ontology (GO) and KEGG pathway enrichment analysis.

\section{GO and pathway analysis}

Enrichment analysis for Biological Process (BP), Molecular Function (MF), Cellular Component (CC) and KEGG
Pathways was performed using Cluster Profiler R Bioconductor package $[39,40]$. GO and pathway terms with adjusted $p$-value $\leq 0.05$ were considered significant. To visualize the $\mathrm{GO}$ enrichment results, GO plot, R package was used [41]. GO plot package calculated z-score using the following formula:

$$
\mathrm{z} \text { score }=(\mathrm{up}-\text { down }) / \sqrt{\text { count }}
$$

where up is the number of up-regulated genes in a GO term and similarly down represents number of downregulated genes in the $\mathrm{GO}$ term. The $\mathrm{z}$-score provides a rough idea about the expression profile of genes within a GO term. The pathways were visualized using the Pathview package to check the differential expression level of the genes in the pathway [42].

\section{Results \\ Characterization of cervical cancer exosomes}

In order to profile the mRNA content of exosomes, the purified exosomes were first visually confirmed by TEM, which revealed the presence of typical cup shaped bilayer vesicles homogenous in size and morphology (Fig. 1A). Further, immunoblotting for exosomal lysates showed the presence of exosome-specific markers like Flotillin 2, HSP70, and Alix (Fig. 1B). The presence of these markers is consistent with the previously reported characteristics of exosomal particles.

\section{Assessment of exosomal RNA quality and integrity}

Qualitative and quantitative estimation of the isolated exosomal RNA was performed using silver staining (Fig. 2A) and spectrophotometry (Fig. 2B and C). The exosomal RNA yield ranged from $100 \mathrm{ng} / \mu \mathrm{l}$ to $600 \mathrm{ng} /$ $\mu \mathrm{l}$ from exosomes without any pre-treatment. However, there was a significant decline upto $60 \%$ in RNA yield when exosomes were pre-treated with RNase (Fig. 2B). In contrast, the RNase - treatment resulted in an improved A260/A280 ratio (Fig. 2C). PCR amplification of $\beta$-actin gene carried out using exosomal RNA from both HPVpositive and HPV-negative cervical cancer cell lines indicated an amplifiable RNA cargo in all the exosomal RNA preparations (Fig. 2D). The location of the primers/ amplicon as deduced by NCBI Primer-BLAST was 9041171 and the full transcript length of $\beta$-actin was $1812 \mathrm{nt}$ (Fig. 2E). Therefore, all the exosomal RNA carried at least 900 nt long transcripts with an intact 3' end poly-A tail. Analysis of exosomal transcript length with intactness/ integrity across different tumor types, has been summarised in Table 1.

\section{Abundance analysis of exosomal transcripts}

Further, mRNA sequencing was performed on total RNA extracted from exosomes to analyse the exosomal 


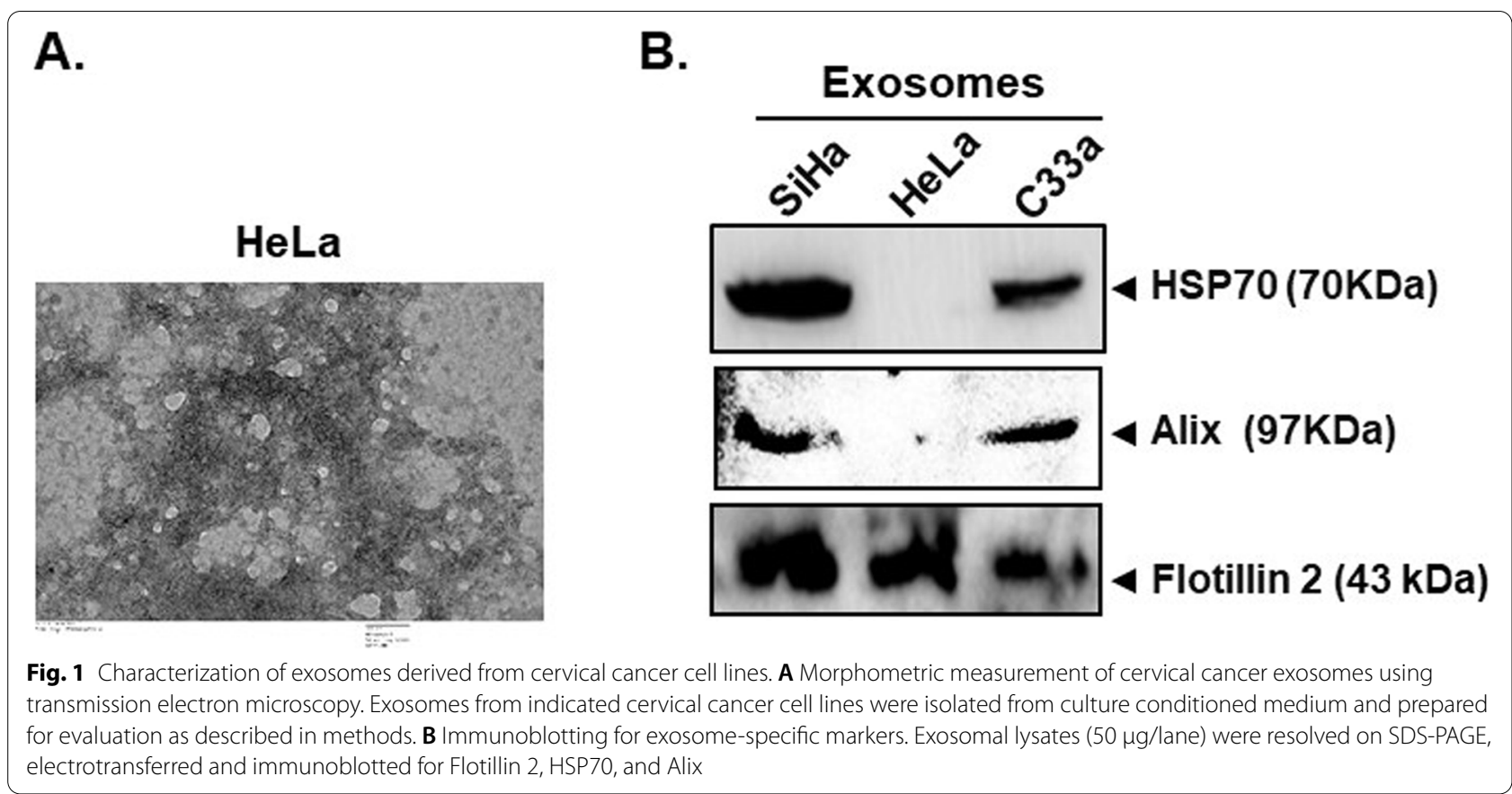

transcript content and abundance. RNA integrity assessed on Agilent 2100 Bioanalyzer, indicated the presence of 100-1000 bp fragments in cDNA prepared (Supplementary Fig. SF1). The QC passed reads mapped onto the indexed combined reference genome of Human (GRCh38.p7), HPV16 and HPV18 on average showed $96.88 \%$ of the reads aligned onto the combined reference genome, whereas 1.07 and $1.60 \%$ of the reads aligned onto HPV16 and HPV18 reference genomes (Supplementary Table ST4). Out of total 606,022 transcripts evaluated, expressed transcripts in each sample with at least 1 mapped read ranged from 533,123 in C33a (87.9\%) to 514,553 in $\mathrm{SiHa}$ (84.9\%) and 245,988 in HeLa (40.59\%) exosomes. The expression similarity between samples as determined by Principal Components Analysis showed that all three samples clustered into three separate groups, with no significant outliers (Fig. 3A). Further, the Pearson's correlation values indicated that HPV16-positive SiHa and HPV-negative C33a exosome samples were positively corelated with each other than with HPV18positive in both the comparison sets (Fig. 3B).

\section{Differential transcript analysis}

Hierarchical clustering showed profiles of exosomal transcripts and indicated that $\mathrm{SiHa}$ and $\mathrm{C} 33 \mathrm{a}$ exosomal transcriptome was similarly clustered as compared to SiHa and HeLa (Fig. 4A). Of 3,099 differentially-exported transcripts, 3,064 were significantly upregulated and 35 were downregulated in HPV-positive exosomes. Next, in the comparison set of exosomes derived from
HPV18-positive cells, 10,912 transcripts were differentially exported. Among these, 6,603 transcripts were significantly upregulated and 4,309 were downregulated. Fourteen transcripts were found exclusively upregulated in $\mathrm{SiHa}$ exosomes, and 1,222 transcripts in HeLa exosomes (Fig. 4B). The expression profile of differentially-exported exosomal transcripts across HPV-negative vs. HPV-positive and HPV16- vs. HPV18-positive groups are represented in volcano plots (Fig. 4C). Overall differential expression of transcripts with top 20 hits, between the indicated comparison sets were identified (Fig. $4 \mathrm{C}$ right panels) and listed in Table 2.

\section{Functional analysis of the exosomal transcripts}

Gene Ontology (GO) enrichment analysis revealed a total of 54 enriched GO categories using a $p$ value cutoff $\leq 0.05$ for 3,099 differentially-exported transcripts in HPV-positive exosomes (Fig. 5A). The significantly altered transcripts belonged to $23 \mathrm{BP}$ categories, $6 \mathrm{MF}$ categories and $25 \mathrm{CC}$ in exosomal compartment of HPVpositive cells. The differentially exported transcripts showed strong association with regulation of ion transport, GTPase activity and axonogenesis among the major BPs; regulation of transporter and tyrosine phosphatase receptor activity among the major MFs; and asymetric synapse, synaptic membrane and glutamatergic synapse among the major CCs. Whereas, among 10,912 differentially-exported transcripts showed enrichment of $56 \mathrm{GO}$, out of which the transcripts belonged to $28 \mathrm{BPs}, 12 \mathrm{MFs}$ and 16 CCs categories (Fig. 5B). Regulation of GTPase 


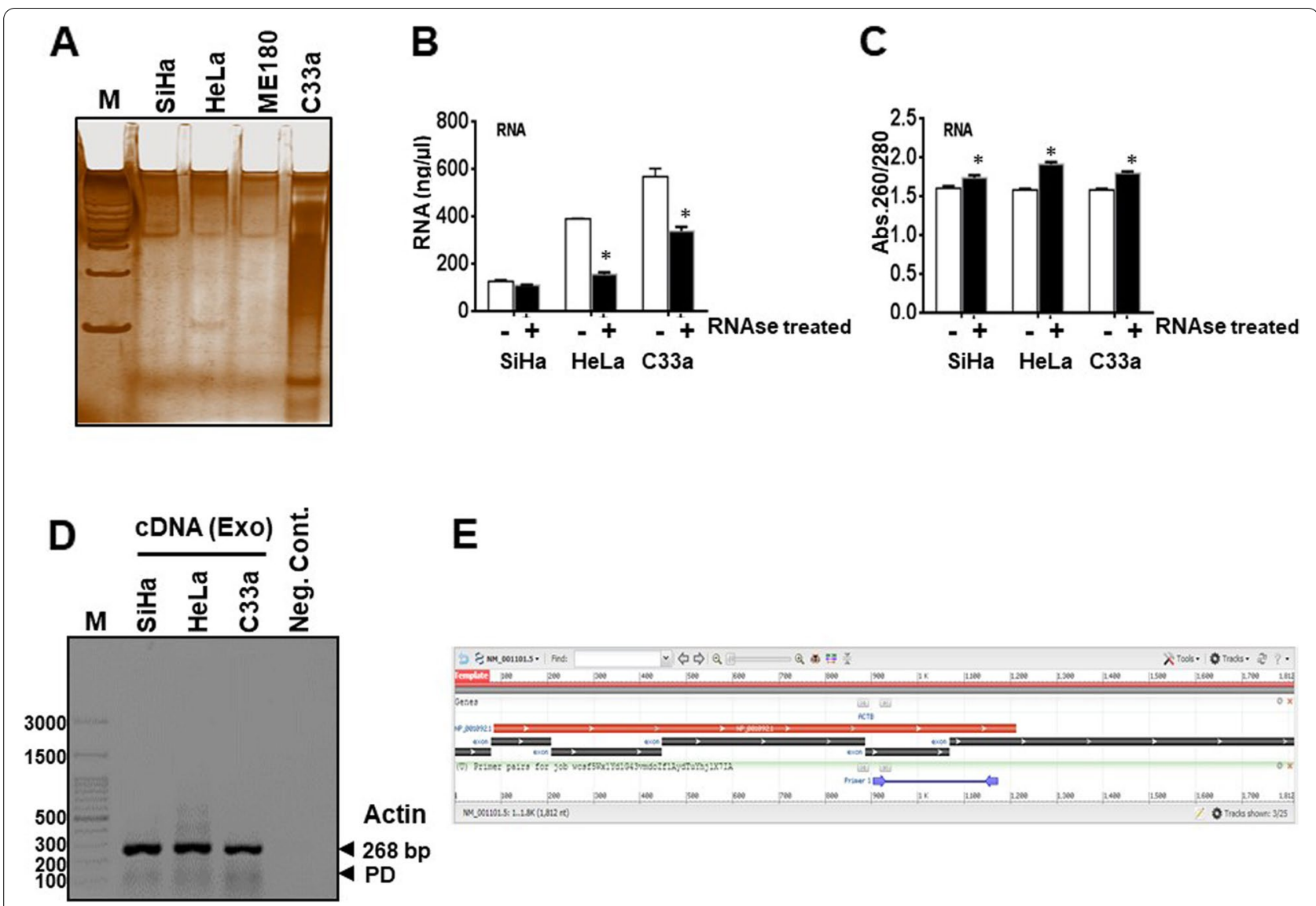

Fig. 2 Qualitative and quantitative assessment of isolated exosomal RNA. RNA estimation in cervical cancer exosomal cargo. A Representative silver staining image of RNA isolated from cervical cancer exosomes. B Spectrophotometric quantification of isolated RNA. Exosomes were pre-treated with RNase before isolation of intra-luminal exosomal RNA to eliminate non-exosomal RNA contamination. C Quality estimation of exosomal RNA using Abs.260/280 ratio. D PCR amplification of $\beta$-actin in CDNA derived from exosomal RNA. Exosomal RNA ( $2 \mu \mathrm{g} / 10 \mu \mathrm{l}$ reaction) from indicated cervical cancer cell lines was used for RT-reaction followed by $\beta$-actin PCR. E NCBI Primer-BLAST graphical view of human $\beta$-actin mRNA and location of the primers used for RT-PCR on $\beta$-actin transcript

activity, post synaptic transmission, sodium ion transmembrane transport were the major BPs, cation channel complex, cell-cell adherens junctions, post synaptic density, emerged as top CCs; and GTPase activity, regulation of neurotransmitter activity were the major MFs that carried the highest z-score. KEGG pathway analysis of differentially-exported transcripts identified 9 pathways in HPV-positive exosomal transcript sets (Supplementary Fig. SF3A-SF3I). The exported transcripts were mainly associated with the regulation of the calcium signaling, cAMP signaling, axon guidance, leukocyte transendothelial migration, circadian entrainment, long term potentiation, glutamatergic synapse, GnRH secretion and morphine addiction. To further validate the observation, we performed RT-PCR to detect the transcripts encoding EPHB1 and its isoform EPHA6, well known transcripts regulating axonogenesis and neuronal growth in exosomes of cervical cancer cells. Our RT-PCR data confirmed detectable levels of EPHB1 transcripts in exosomes of HPV positive cells, however, the EPHA6 transcripts were not detected in these exosomes (Fig. 6).

\section{Identification of HPV transcripts in exosomal cargo}

Next we examined, the exosomal compartment for export of HPV transcripts using all mapped and uniquely mapped reads on Integrative Genomics Viewer (IGV). The data showed presence of low abundance reads sparingly scattered over the reference transcriptomes of HPV16 and HPV18 in SiHa and HeLa exosomes, respectively (Fig. 7A, B). However, these number were consistently higher than the $\mathrm{C} 33 \mathrm{a}$ exosomal reads which seldom mapped to HPV16 or HPV18 genomes. Among others, E5 region showed highest representation in $\mathrm{SiHa}$ exosomes. However, a few reads were also detected in regions corresponding to HPV E6 and E7 regions in both $\mathrm{SiHa}$ and HeLa exosomal compartments. 
Table 1 Estimation of intactness or integrity of transcript length using reverse transcriptase mediated cDNA preparation using $3^{\prime}$ end followed by region specific PCR

\begin{tabular}{|c|c|c|c|c|c|}
\hline Tumor type (Reference) & $\begin{array}{l}\text { Transcript examined in } \\
\text { exosomal RNA }\end{array}$ & $\begin{array}{l}\text { Full length } \\
\text { mRNA (bp) }\end{array}$ & $\begin{array}{l}\text { Nucleotide position } \\
\text { showing amplification }\end{array}$ & $\begin{array}{l}\text { Product length } \\
\text { (bp) }\end{array}$ & $\begin{array}{l}\text { Transcript } \\
\text { coverage } \\
\text { (nt) }\end{array}$ \\
\hline \multirow[t]{3}{*}{ Glioblastoma [14] } & GAPDH & 1231 & $82-256$ & 175 & 1150 \\
\hline & EGFR/EGFRvIII PCR1 & 1575 & $216-1447$ & 1232 & 1360 \\
\hline & EGFR/EGFRvIII PCR2 & 1775 & $262-1414$ & 1153 & 1514 \\
\hline \multirow[t]{5}{*}{ Colorectal cancer [20] } & $\beta$-actin & 1812 & $353-479$ & 127 & 1460 \\
\hline & $\beta$-catenin (CTNNB1) & $\begin{array}{l}3488 \\
3197\end{array}$ & $\begin{array}{l}206-471 \\
206-339\end{array}$ & $\begin{array}{l}266 \\
134\end{array}$ & $\begin{array}{l}3283 \\
2992\end{array}$ \\
\hline & RAB13 & 1164 & $182-254$ & 73 & 983 \\
\hline & CXCR4 & 1904 & 116-188 & 73 & 1789 \\
\hline & MYC & 3721 & $371-440$ & 70 & 3351 \\
\hline \multirow[t]{5}{*}{ Breast Cancer [21] } & EEF1A1 & 3512 & $1329-1438$ & 110 & 2184 \\
\hline & FTH1 & 1203 & $440-573$ & 134 & 764 \\
\hline & FTL & 871 & $384-529$ & 146 & 488 \\
\hline & RAB13 & 1347 & $785-891$ & 107 & 563 \\
\hline & RPL28 & 4209 & $215-338$ & 124 & 3995 \\
\hline Prostate cancer [49] & GAPDH & 1285 & $950-1050$ & 101 & 336 \\
\hline Cervical cancer (present study) & $\beta$-actin & 1812 & $904-1171$ & 268 & 908 \\
\hline
\end{tabular}

\section{Evaluation of HPV oncogene transcripts in exosomal cargo} In order to validate the presence of HPV E6 and E7 in exosomal transcripts, RT-PCR was performed on the RNA isolated from cervical cancer exosomes. The PCR primers that specifically target either E6 or E7 regions of HPV16 or HPV18 in a type-specific manner could amplify full length transcripts and different splice variants as indicated (Fig. 8AR). Notably, both the cervical cancer cell lines showed type-specific presence of E6 and E7 transcripts in their cellular compartment; however, we could not detect E6 and E7 transcripts in exosomes of SiHa cells, when loaded with the cDNA from cells as internal control (Fig. 8BR). In contrast, HeLa exosomes consistently showed amplification of 245 bp region suggesting presence of HPV transcripts corresponding to E6*I $\left(233^{\wedge} 416\right)$ that was found overrepresented in HeLa cells. However, full length HPV18 E6 (428 bp) that was expressed in HeLa cellular compartment in low abundance was undetectable in exosomal compartment. Further, to check if the cytotoxic drugs influence the export of HPV transcripts in cervical cancer exosomes, cervical cancer cells were treated with either 5-FU or cisplatin at the $\mathrm{IC}_{50}$ dose [SiHa: $(17.58 \mu \mathrm{M} ; 5-\mathrm{FU}$ and $24.14 \mu \mathrm{M}$ : cisplatin); HeLa: (15.31 $\mu \mathrm{M}$; 5-FU and $6.82 \mu \mathrm{M}$ : cisplatin)] for a period of $48 \mathrm{hrs}$. Against our anticipation, we did not detect HPV E6 or E7 in SiHa or HeLa exosomes post-drug treatment (Fig. 9A). Contrarily, we observed a decline in the HPVE6*I transcripts in exosomes of drugtreated HeLa cells (Fig. 9B).

\section{Discussion}

The investigation showed presence of pro-tumorigenic transcripts in cervical cancer exosomes. The exosomal RNA contained poly A-tailed transcripts that successfully reverse transcribed and were PCR amplifiable. NGS data showed that upto $88 \%$ of human transcriptome with at least one mapped read [533,123 in C33a (87.9\%) to 514,553 in $\mathrm{SiHa}(84.9 \%)$ and 245,988 in HeLa (40.59\%)] was represented in the exosomal cargo. Analysis of intersample variation revealed a small subset of differentiallyexported transcripts in HPV-negative and HPV-positive cell-derived exosomes. In contrast, the exosomal cargo of HPV16- and HPV18-positive cells showed a large number of differentially-exported transcripts. Our attempt to find HPV-specific transcripts in exosomal compartment exhibited low abundance reads that mapped to different regions of HPV transcriptome. RT-PCR validation confirmed the presence of HPV E6*I in HeLa exosomes.

Herein, we report for the first time the export of mRNA in the cervical cancer exosomes from tumor cells. Export of PCR-amplifiable tumor-derived mRNA has been previously reported in glioblastoma [14], colorectal [20], breast [21], and prostate cancer [22] as well as in transfomed cell line HEK 293T [19]. However, a quantitative assessment of the RNA yield from exosomes was consistently lacking in all these studies. Our data demonstrated a 4-5 fold difference in exosomal RNA yield among different cell lines tested. Although exosomal release is a regulated process controlled by GPCR's [43], the reason for 


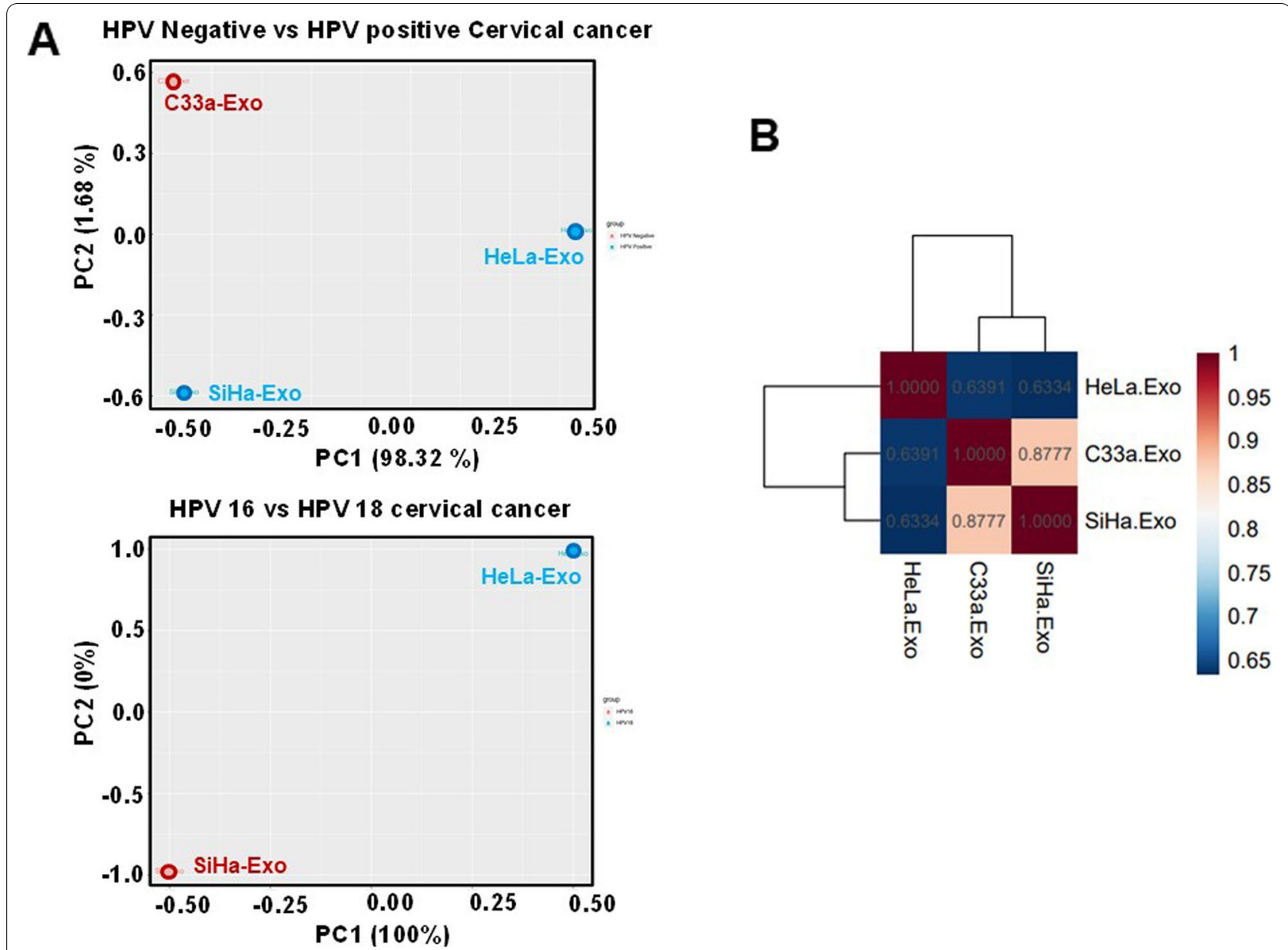

Fig. 3 Analysis of overall distribution of transcript content in exosomal compartment of HPV-negative and HPV-positive cervical cancer cells. A Principal Component Analysis (PCA) of exosomal transcripts in HPV-positive vs. HPV-negative cervical cancer cells (upper panel) and HPV16-positive SiHa cells vs. HPV18-positive HeLa cells (lower panel) B. Pearson's Correlation plot

a differential content of packaged exosomal RNA is not known and may primarily depend on the metabolic state of the parent cell. Total RNA from untreated exosomes was found to contain cell-free nucleic acids that could have influenced the study outcome. RNase pretreatment reduced the total exosomal RNA yield by 7\% as reported by an earlier study [14]. The decrease in RNA yield upto $60 \%$ on treatment with RNAse perhaps indicates the presence of RNA from cell free nucleic acids. Nevertheless, RNase pre-treatment resulted in an improvement of A260/A280 ratio. Silver staining of RNA from these exosomes revealed a broad range of RNA sizes. As reported earlier [14], the exosomal RNA lacked characteristic rRNA bands routinely detected in the cellular RNA preparations.

The length of cervical cancer exosomal mRNA varied between 170 and $984 \mathrm{nt}$. Maximum length of mRNA reported in exosomes is still debatable. High throughput studies failed to discriminate between full length and fragmented mRNA's in exosomes [19, 21]. The intact cellular mRNAs on an average measure $2000 \mathrm{nt}$ with a range of 350 and 12,000 nt [44]. Earlier, exosomal mRNA appeared predominantly fragmented and 3'-UTRsenriched [45]. However, a comparative RNA length analysis carried out on glioma stem cell and their respective exosomes showed a specific enrichment of 3'UTR transcripts, without any preference for shorter transcripts in the exosomal fractions [46]. RT-PCR using cDNA intermediates derived from poly-A transcripts can permit a direct estimation of the exosomal mRNA length. These observations suggest presence of intact, biologicallyactive transcripts like beta actin in the exosomal compartment. The presence of beta actin and GAPDH has already been reported in the mouse and human exosomes respectively (http://www.exocarta.org/).

Other studies using alternate NGS library preparation strategies have shown that $58 \%$ of the non-rRNA reads of breast cancer exosomal RNA could map to known genes 


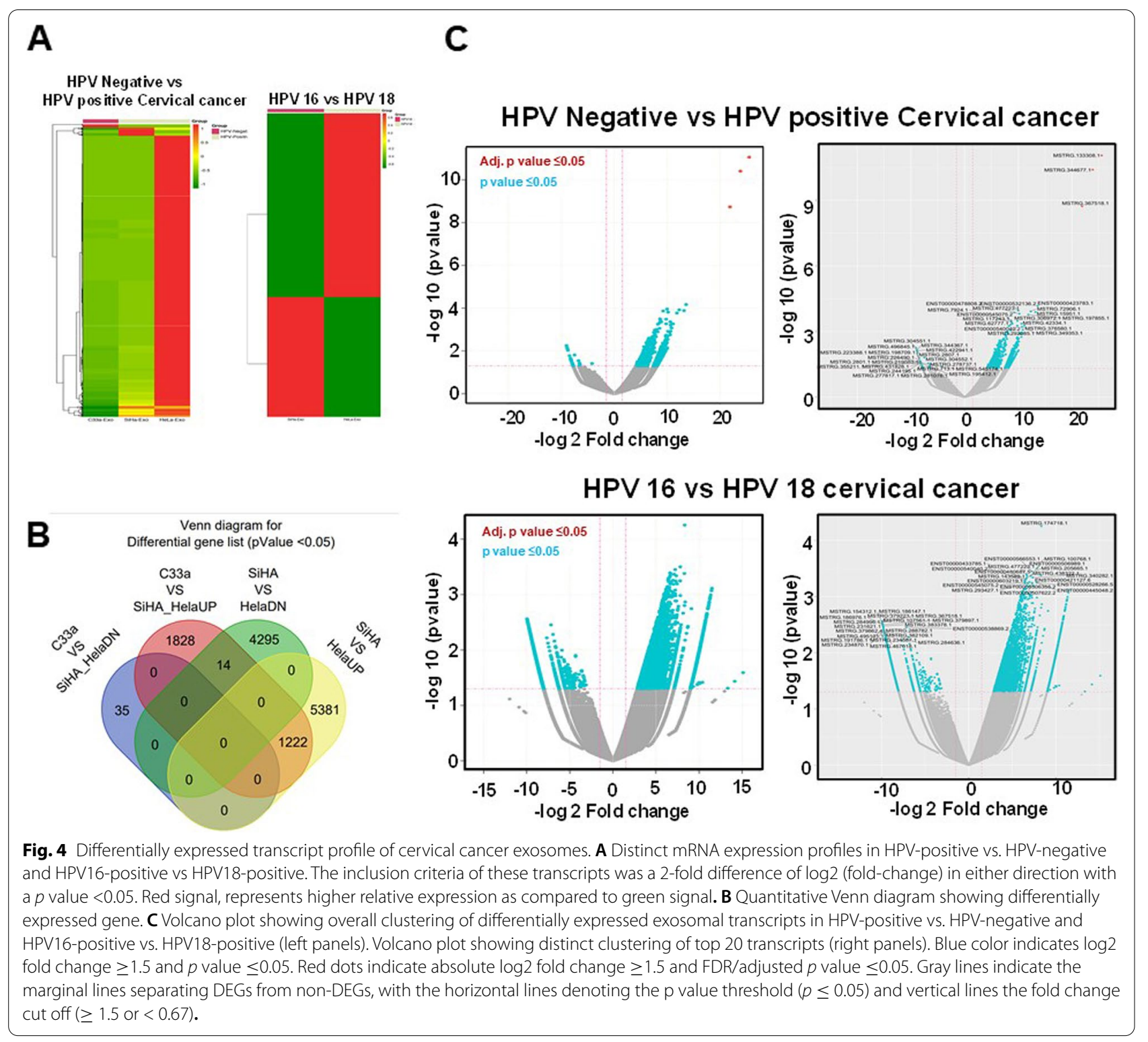

[21]. Studies based on high resolution microarray platforms $[19,20]$ also showed presence of several transcripts in exosomes; however, the magnitude of different transcripts reported in exosomal cargo was comparatively lesser.

PCA plot and corelation similarity index of the normalised read counts (C33a vs $\mathrm{SiHa}$ : 0.8777> C33a vs HeLa: 0.6391> SiHa vs HeLa: 0.6334) showed distinct qualitative and quantitative transcript profile of all the three exosomal samples. SiHa and C33a exosomal samples displayed lower intra sample variance as compared to $\mathrm{SiHa}$ vs. HeLa exosomal transcripts. Such pattern might be an outcome of cancer cell origin. C33a (ATCC-HTB-31) and $\mathrm{SiHa}$ cells (ATCC-HTB-35) originated from squamous cell carcinoma, whereas HeLa cells (ATCC-CRM-CCL-2) had adenocarcinoma origin. Both the diseases are known to express a distinct molecular profile and separate clinico-pathological spectrum [47].

Functional gene analysis using GO and pathway analysis using KEGG unexpectedly revealed enriched transcripts playing key roles in several biological and molecular functions related to nerve growth, neuronal functions and cell migration. Differentially exported transcripts showed the gene annotations of regulating synaptic membrane potential, calcium signaling, cAMP signaling, axon guidance, leukocyte transendothelial migration, circadian entrainment, long term potentiation, glutamatergic synapse, GnRH secretion and 
Table 2 List of top 20 upregulated and downregulated transcripts in exosomal RNA from HPV-positive cells

\begin{tabular}{|c|c|c|c|c|c|c|}
\hline \multirow[t]{2}{*}{ Fragment Id } & \multirow[t]{2}{*}{ Gene Name } & \multirow[t]{2}{*}{ Gene Description } & \multicolumn{3}{|c|}{ Enrichment Score (FPKM) } & \multirow[t]{2}{*}{$P$ value } \\
\hline & & & C33a-Exo & SiHa-Exo & HeLa-Exo & \\
\hline \multicolumn{7}{|l|}{ Upregulated } \\
\hline MSTRG.367518.1 & TBC1D9 & TBC1 domain family member 9 & 0.0 & 318.0 & 0.0 & 1.87E-09 \\
\hline MSTRG.344677.1 & EVC2 & EvC ciliary complex subunit 2 & 0.0 & 1313.3 & 0.0 & 3.99E-11 \\
\hline MSTRG.133308.1 & - & - & 0.0 & 0.0 & 4341.5 & $8.89 \mathrm{E}-12$ \\
\hline ENST00000423783.1 & ACTG1P24 & - & 0.0 & 3.8 & 3570.2 & $6.77 \mathrm{E}-05$ \\
\hline ENST00000478808.2 & USP30-AS1 & - & 3.2 & 10.6 & 7285.6 & 0.000154 \\
\hline ENST00000532136.2 & OR5AM1P & - & 4.7 & 30.0 & 9612.9 & 0.000111 \\
\hline MSTRG.477223.1 & RP11-11N9.4 & - & 17.4 & 195.9 & 20881.6 & 0.000136 \\
\hline MSTRG.72906.1 & - & - & 0.0 & 28.8 & 1423.9 & 0.00012 \\
\hline MSTRG.15951.1 & NFIA & nuclear factor I A & 0.0 & 1.9 & 2700.7 & 0.00013 \\
\hline MSTRG.306972.1 & - & - & 3.2 & 5.0 & 5714.5 & 0.000327 \\
\hline MSTRG.197855.1 & - & - & 0.0 & 40.1 & 1029.7 & 0.000169 \\
\hline MSTRG.42334.1 & - & - & 0.0 & 294.2 & 154.7 & 0.000437 \\
\hline MSTRG.376580.1 & - & - & 0.0 & 16.3 & 633.7 & 0.000542 \\
\hline MSTRG.349353.1 & - & - & 0.0 & 50.7 & 414.9 & 0.000613 \\
\hline MSTRG.292085.1 & $\mathrm{CH} 507-513 \mathrm{H} 4.1$ & - & 1.6 & 2.5 & 2853.5 & 0.000539 \\
\hline ENST00000540040.2 & MTRNR2L1 & MT-RNR2-like 1 & 58.5 & 380.0 & 35309.4 & 0.000563 \\
\hline MSTRG.62777.1 & - & - & 4.7 & 47.6 & 3485.3 & 0.000487 \\
\hline MSTRG.117243.1 & ANKS1B & ankyrin repeat and sterile alpha motif domain containing 1B & 3.2 & 27.5 & 2961.0 & 0.000436 \\
\hline MSTRG.7924.1 & LUZP1 & leucine zipper protein 1 & 1.6 & 83.9 & 1241.0 & 0.00037 \\
\hline ENST00000545075.2 & MTRNR2L10 & MT-RNR2-like 10 & 24.5 & 213.5 & 19438.8 & 0.000315 \\
\hline \multicolumn{7}{|l|}{ Downregulated } \\
\hline MSTRG.496845.1 & RP11-661A12.12 & - & 69.6 & 0.0 & 0.0 & 0.016636 \\
\hline MSTRG.304551.1 & APOBEC $3 \mathrm{~A}$ & apolipoprotein B mRNA editing enzyme catalytic subunit $3 \mathrm{~A}$ & 104.3 & 0.0 & 0.0 & 0.005624 \\
\hline MSTRG.223388.1 & - & - & 59.3 & 0.0 & 0.0 & 0.024676 \\
\hline MSTRG.198709.1 & - & - & 61.6 & 0.0 & 0.0 & 0.022445 \\
\hline MSTRG.226490.1 & CTD-2189E23.1 & - & 60.9 & 0.0 & 0.0 & 0.023159 \\
\hline MSTRG.344367.1 & - & - & 95.6 & 0.0 & 0.0 & 0.007161 \\
\hline MSTRG.2801.1 & - & - & 58.5 & 0.0 & 0.0 & 0.025481 \\
\hline MSTRG.219083.1 & OACYLP & - & 58.5 & 0.0 & 0.0 & 0.025481 \\
\hline MSTRG.355211.1 & UGT2B17 & UDP glucuronosyltransferase family 2 member B17 & 57.7 & 0.0 & 0.0 & 0.02632 \\
\hline MSTRG.431828.1 & - & - & 56.9 & 0.0 & 0.0 & 0.027195 \\
\hline MSTRG.244195.1 & - & - & 55.3 & 0.0 & 0.0 & 0.029056 \\
\hline MSTRG.277817.1 & AGAP1 & $\begin{array}{l}\text { ArfGAP with GTPase domain, ankyrin repeat and PH domain } \\
1\end{array}$ & 56.9 & 0.0 & 0.0 & 0.027195 \\
\hline MSTRG.281076.1 & SNAP25-AS1 & SNAP25 antisense RNA 1 & 50.6 & 0.0 & 0.0 & 0.035696 \\
\hline MSTRG.195412.1 & MYO15A & myosin XVA & 55.3 & 0.0 & 0.0 & 0.029056 \\
\hline MSTRG.545174.1 & - & - & 56.9 & 0.0 & 0.0 & 0.027195 \\
\hline MSTRG.278737.1 & THAP4 & THAP domain containing 4 & 83.8 & 1.3 & 0.0 & 0.028536 \\
\hline MSTRG.304552.1 & APOBECЗА & apolipoprotein B mRNA editing enzyme catalytic subunit 3A & 88.5 & 0.6 & 0.0 & 0.015573 \\
\hline MSTRG.2807.1 & - & - & 86.9 & 0.0 & 0.0 & 0.009282 \\
\hline MSTRG.422941.1 & FILIP1 & filamin A interacting protein 1 & 93.3 & 0.0 & 0.0 & 0.007671 \\
\hline
\end{tabular}

morphine addiction. Axon guidance and axonogenesis are important pre-requisites of cancer innervation and tumor exosomes containing EphrinB1 have been described to promote axonogenesis axonogenesis [48].
Tumor innervation is associated with poor clinical outcomes in several solid cancers including cervical and head and neck squamous cell carcinoma [48, 49]. Interestingly, our RT-PCR analysis showed presence of EPHB1 



in the exosomal cargo of HPV-positive cervical cancer cells. Therefore, exosomal cargo of HPV-positive cells might be responsible for favouring neurite outgrowth. However, these assumptions require further functional validation.
Exosomes from HPV-positive cells contained high levels of TBC1D9, EVC2, RP11-11N9.4, NFIA, ANKS1B, LUZP1, MTRNR2L10 and MTRNR2L1 among the known coding transcripts. Although ectopic expression/ export of these genes in cervical cancer or HPV infection 


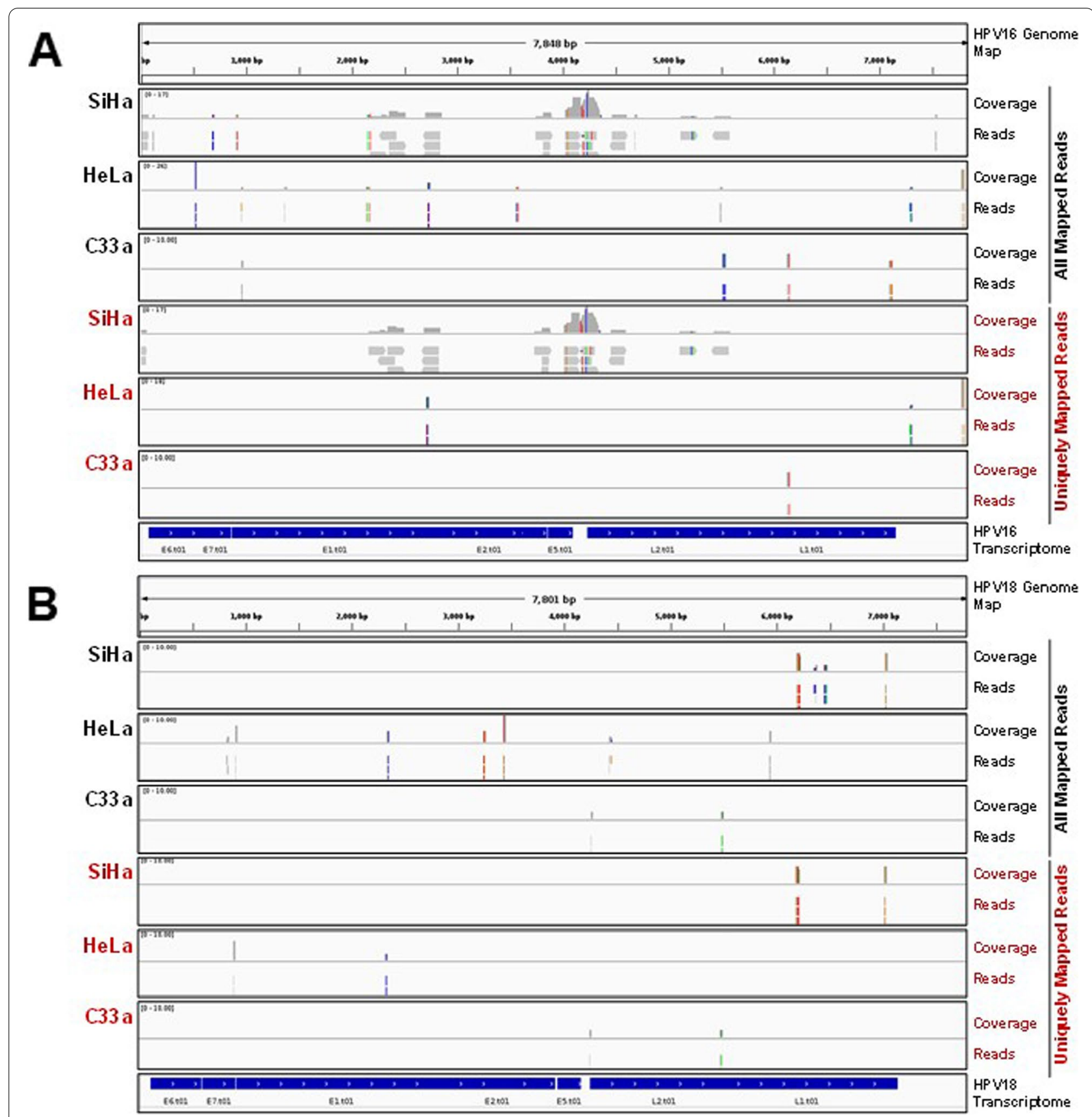

Fig. 7 Enrichment of HPV-related reads in exosomal transcripts. Integrated Genome Viewer snapshots showing mapping of all mapped reads and uniquely mapped reads detected in SiHa and HeLa exosomes to HPV16 (A) or HPV18 (B) reference genomes, respectively

remains unreported, some correlates suggest a potential tumor promoting role of some of them. EVC2 positively modulated Hedgehog (Hh) signaling pathway by forming complex with SMO protein and transduced Hh signaling in recipient breast cancer cells [50]. Notably, elevated Hh signaling is abberently and constitutively active in cervical cancer cells [32]. Similarly, enrichment of circANKS1B in HPV-positive cervical cancer exosomes may play a role in influencing cellular migration and invasion. circANKS1B increases the expression of transcription factor USF1, which upregulates TGF- $\beta 1$ expression resulting in activated TGF- $\beta 1 / \mathrm{Smad}$ signaling and EMT in breast cancer [51]. Also, circANKS1B regulates FOXM1 expression and promotes cell migration and invasion by functioning as a sponge of the miR-149 in colorectal cancer [52]. ANKS1B was identified as a novel 


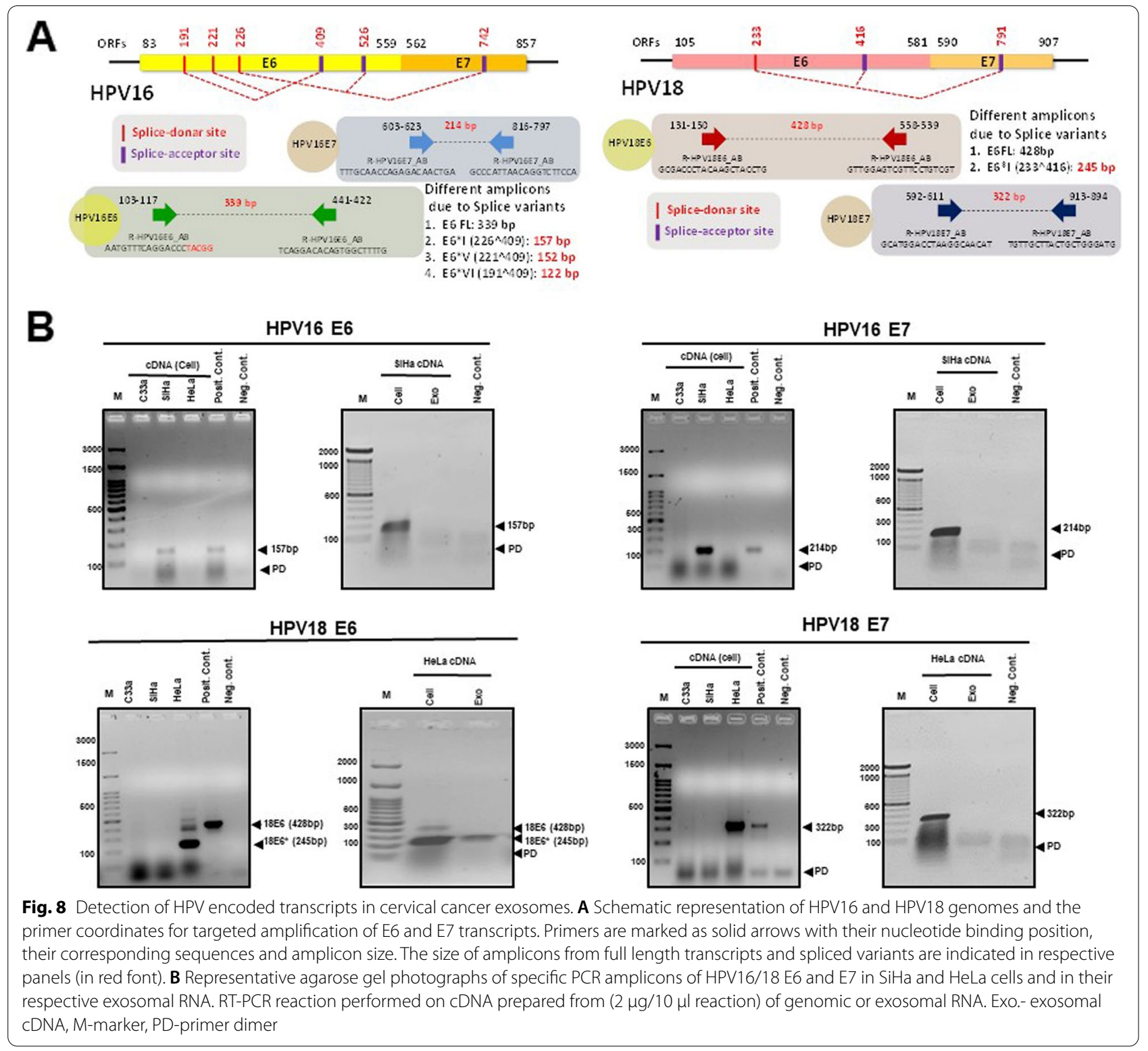

KRIT1 interacting protein that selectively controlled endothelial permeability [53]. Likewise, actin stabilising protein LUZP1, along with EPLIN, is known to alter cellular physiologies like EMT transition and cellular migration [54]. Therefore, differentially-exported exosomal transcripts from HPV-positive cervical cancer, may collectively contribute to tumor progression.

Cervical cancer being an HPV E6/E7-driven cancer, the HPV transcripts were highly expected in the exosomal compartment. Contrary to our hypothesis, a low enrichment of the viral transcripts was noted and the reads aligned sparsely and randomly over HPV16 and HPV18 reference genome. In contrast, abundant cellular expression of E6 and E7 was noted in both SiHa and HeLa cells. These transcripts were not detectable in $\mathrm{SiHa}$ exosomes, but HeLa exosomal RNA showed a specific splice variant HPV18 E6*I. Further, there was no alteration in exosomal E6/E7 transcript profile even if the cells were rendered to oxidative stress, a phenomenon known to induce exosome secretion and increase exosomal nucleic acid content $[55,56]$. Nevertheless, detection of $\mathrm{E} 6 * \mathrm{I}$ is a remarkable finding as it is the most dominant splice variant reported in primary HPV infection model [57] and increased significantly from $5-50 \%$ of all HPV mRNA in CIN2 to SCC samples during cervical cancer progression [58]. E6"I is 


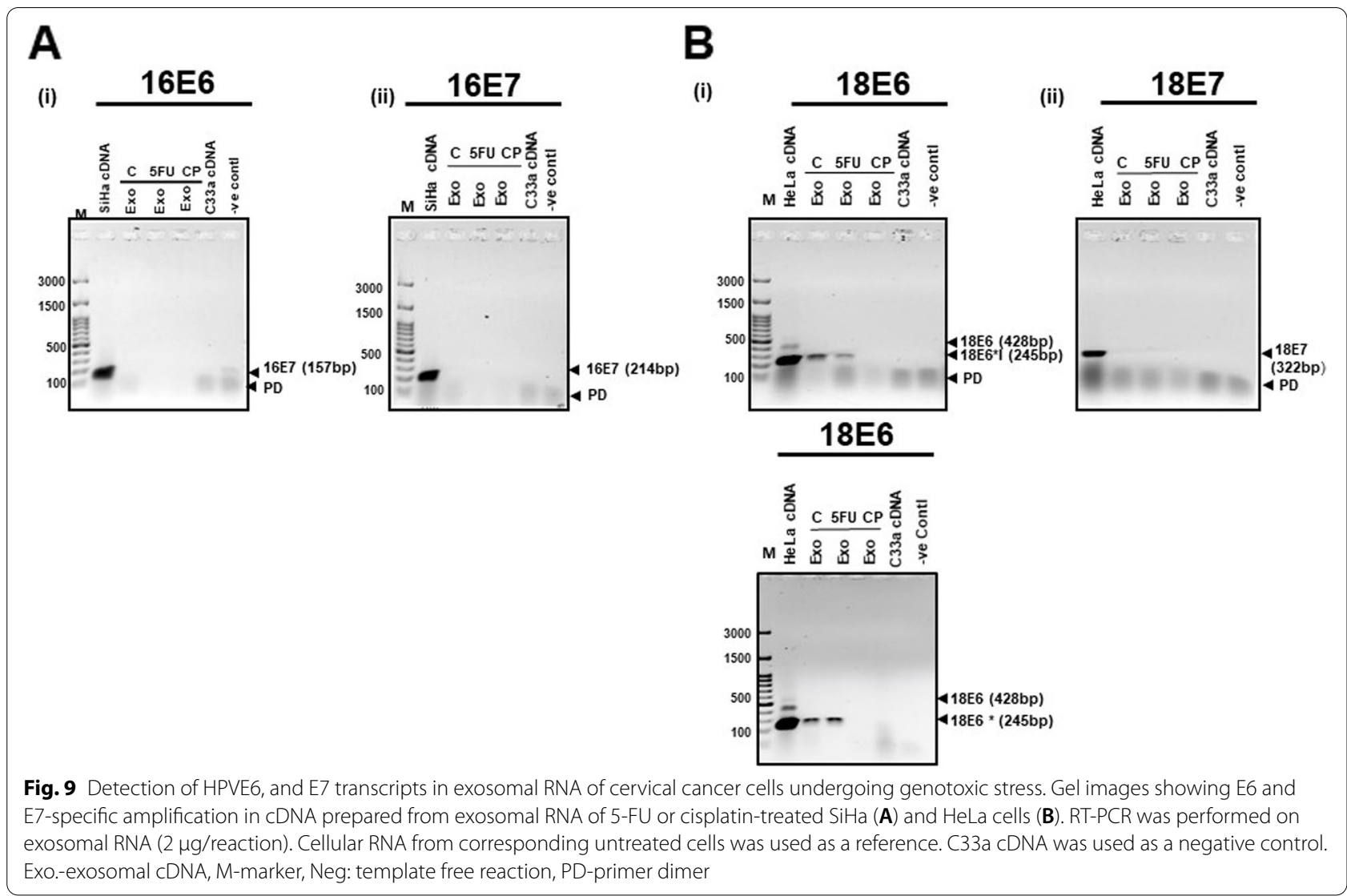

known to play a prominent role in anti-apoptosis [59] and can potentially code for functional E7 protein [60]. Therefore, E6*I transcript which is predicted to have an important role in establishment of viral infection and early phase of viral propagation, may be executing its effect via exosome-mediated export and this observation demands further investigation.

\section{Conclusion}

Overall, our study provides a detailed transcript profile of cervical cancer exosomes and discovered some remarkable differences in the pro-tumorigenic content and enrichment of mRNA of both cellular and viral origin. These signature mRNA along with other exosomespecific biomolecules can serve as disease biomarkers for cervical cancer progression. Our data showed a specific enrichment of truncated HPV18 E6*I mRNAs in HeLa exosomes, a lead which will serve as primer for detailed investigations addressing conditioning of constituent cells in the tumor microenvironment and will serve as a milestone in mRNA-based exosomal biomarker discovery in cervical cancer.

\section{Abbreviations}

CaCx: Cervical cancer; HPV: Human papillomavirus; d-FBS: Depleted fetal bovine serum; BSA: Bovine serum albumin; PBS: Phosphate-buffered saline; BCA: Biocinchoninic acid; SDS: Sodium dodecyl sulphate; PVDF: Poly vinylidene fluoride; HRP: Horseradish peroxidase; ECL: Enhanced chemiluminescent; EDTA: Ethylenediaminetetraacetic acid; PAGE: Polyacrylamide gel electrophoresis; TEM: Transmission electron microscopy; NGS: Next generation sequencing; RIN: RNA integrity number; GO: Gene ontology; KEGG: Kyoto encyclopedia for gene and genomes; BLAST: Basic local alignment search tool; NCBI: National Center for Biotechnology; MF: Molecular Function; CC: Cellular Component; BP: Biological Process; PCA: Principal component analysis; CIN: Cervical intraepithelial neoplasia; RT-PCR: Reverse transcriptase PCR; IncRNA: Long non-coding RNA; TUG-1: Taurine upregulated-1; DNA: Deoxyribo nucleic acid; PCR: Polymerase chain reaction; RNA: Ribo nucleic acid.

\section{Supplementary Information}

The online version contains supplementary material available at https://doi. org/10.1186/s12885-022-09262-4.

Additional file 1: Table SI. List of antibodies used for immunoblotting (IB) experiments. Table SII: List of primers used in the study along with their sequence and amplicon size. Table SIII. Summary of raw sequence data and quality. Table SIV. Read alignment statistics with Combined Genome (GRCh38.p7, HPV16 \& HPV18).

Additional file 2: SF1. Exosomal RNA characterization. SF2. Relationship between the assembled transcripts and closely related reference transcripts. SF3. KEGG Analysis of differentially expressed transcripts in exosomal RNA of HPV-negative vs. HPV-positive cervical cancer cells. SF4. Original uncropped blots for Fig. 1B 


\section{Acknowledgements}

We are thankful to Dr. Aman Sharma, ExoCan Healthcare Technologies Pvt. Ltd., Pune Maharashtra for extending his support for providing primers and facility during the course of study. We acknowledge Mr. Suhail Chhakara for manuscript review and language corrections.

\section{Authors' contributions}

Conceptualization: $A C B$; Data curation: $A B, A C B$; Formal analysis: $A B, J Y, K T, N A$, $A C, T S, M J, W$; Funding acquisition: ACB. Investigation: $A B, J Y, A C B$. Methodology: $A B, J Y, T T, K T, N A, A C, T S, M J$; Project administration: $A C B$; Resources: $A C B$, Supervision: $A C B$; Validation: JY, TT, ACB; Visualization: $A B, J Y, T T, K T, N A, A C B$; Writing original draft: $A B, A C B$; Review and editing: $A B, A C B$. The author(s) read and approved the final manuscript.

\section{Funding}

Financial support from Science and Engineering Research Board Department of Science and Technology, Government of India to ACB (DST-SERB (EMR/2017/004018/BBM). Study was partly supported by research grant from ICMR (sanction no.- 5/13/38/2014-NCD-III) to ACB, ICMR-Senior Research Fellowship to AB (2017-2834/CMB/BMS), Senior Research Fellowship to JY (09/045(1629)/2019-EMR-I) and NA (09/045(1622)/2019-EMR-I), Council of Scientific and Industrial Research (CSIR), Junior Research Fellowship to TT by Department of Science and Technology, India (EMR/2017/004018/BBM), Senior Research Fellowship to TS (2061430699 22/06/2014(i) EU-V), and AC [573(CSIR-UGC NET JUNE 2017)] by University Grants Commission (UGC), Senior Research Fellowship to KT(5/13/38/2014 NCDIII-Eoffice73143), and MJ (3/2/2/278/2014-NCDIII) by Indian Council of Medical Research.

\section{Availability of data and materials}

The data sets used and or/analyzed during the current study are available from the corresponding author on reasonable request.

\section{Declarations}

\section{Ethics approval and consent to participate}

Not Applicable

\section{Consent for publication}

Not Applicable

\section{Competing interests}

The authors declare that there is no competing/conflicts of interest.

\section{Author details}

${ }^{1}$ Molecular Oncology Laboratory, Department of Zoology, University of Delhi (North Campus), Delhi 110007, India. ${ }^{2}$ Department of Physiology and Pharmacology, Karolinska Institute, Stockholm, Sweden.

Received: 6 September 2021 Accepted: 25 January 2022

Published online: 11 February 2022

\section{References}

1. Sundstrom K, Elfstrom KM. Advances in cervical cancer prevention: efficacy, effectiveness, elimination? PLoS Med. 2020;17(1):e1003035.

2. Arbyn M, Weiderpass E, Bruni L, de Sanjose S, Saraiya M, Ferlay J, et al. Estimates of incidence and mortality of cervical cancer in 2018: a worldwide analysis. Lancet Glob Health. 2020;8(2):e191-203.

3. Meldolesi J. Exosomes and ectosomes in intercellular communication. Curr Biol. 2018;28(8):R435-44.

4. Whiteside TL. Tumor-derived exosomes and their role in cancer progression. Adv Clin Chem. 2016;74:103-41.

5. Mashouri L, Yousefi $H$, Aref AR, Ahadi AM, Molaei F, Alahari SK. Exosomes: composition, biogenesis, and mechanisms in cancer metastasis and drug resistance. Mol Cancer. 2019;18(1):75.

6. Wang H, Wei M, Kang Y, Xing J, Zhao Y. Circular RNA circ_PVT1 induces epithelial-mesenchymal transition to promote metastasis of cervical cancer. Aging. 2020;12(20):20139-51.
7. Zhou CF, Ma J, Huang L, Yi HY, Zhang YM, Wu XG, et al. Cervical squamous cell carcinoma-secreted exosomal miR-221-3p promotes lymphangiogenesis and lymphatic metastasis by targeting VASH1. Oncogene. 2019;38(8):1256-68.

8. Zhang L, Li H, Yuan M, Li M, Zhang S. Cervical cancer cells-secreted exosomal microRNA-221-3p promotes invasion, migration and angiogenesis of microvascular endothelial cells in cervical cancer by down-regulating MAPK10 expression. Cancer Manag Res. 2019;11:10307-19.

9. Wu XG, Zhou CF, Zhang YM, Yan RM, Wei WF, Chen XJ, et al. Cancerderived exosomal miR-221-3p promotes angiogenesis by targeting THBS2 in cervical squamous cell carcinoma. Angiogenesis. 2019;22(3):397-410.

10. Raji GR, Sruthi TV, Edatt L, Haritha K, Sharath Shankar S, Sameer Kumar VB. Horizontal transfer of miR-106a/b from cisplatin resistant hepatocarcinoma cells can alter the sensitivity of cervical cancer cells to cisplatin. Cell Signal. 2017;38:146-58.

11. Luo $X$, Wei J, Yang FL, Pang XX, Shi F, Wei YX, et al. Exosomal IncRNA HNF1A-AS1 affects cisplatin resistance in cervical cancer cells through regulating microRNA-34b/TUFT1 axis. Cancer Cell Int. 2019;19:323.

12. Zhang J, Jiang M, Qian L, Lin X, Song W, Gao Y, et al. The STAT3-miR-223TGFBR3/HMGCS1 axis modulates the progression of cervical carcinoma. Mol Oncol. 2020;14(9):2313-31.

13. Jeppesen DK, Fenix AM, Franklin JL, Higginbotham JN, Zhang Q, Zimmerman $L$, et al. Reassessment of exosome composition. Cell. 2019;177(2):428-445 e418.

14. Skog J, Wurdinger T, van Rijn S, Meijer DH, Gainche L, Sena-Esteves M, et al. Glioblastoma microvesicles transport RNA and proteins that promote tumour growth and provide diagnostic biomarkers. Nat Cell Biol. 2008;10(12):1470-6.

15. O'Brien K, Breyne K, Ughetto S, Laurent LC, Breakefield XO. RNA delivery by extracellular vesicles in mammalian cells and its applications. Nat Rev Mol Cell Biol. 2020;21(10):585-606.

16. Zhang J, Liu SC, Luo XH, Tao GX, Guan M, Yuan H, et al. Exosomal long noncoding RNAs are differentially expressed in the cervicovaginal lavage samples of cervical cancer patients. J Clin Lab Anal. 2016;30(6):1116-21.

17. Ratajczak J, Miekus K, Kucia M, Zhang J, Reca R, Dvorak P, et al. Embryonic stem cell-derived microvesicles reprogram hematopoietic progenitors: evidence for horizontal transfer of mRNA and protein delivery. Leukemia. 2006;20(5):847-56.

18. Deregibus MC, Cantaluppi V, Calogero R, Lo lacono M, Tetta C, Biancone $L$, et al. Endothelial progenitor cell derived microvesicles activate an angiogenic program in endothelial cells by a horizontal transfer of mRNA Blood. 2007;110(7):2440-8.

19. Li J, Chen X, Yi J, Liu Y, Li D, Wang J, et al. Identification and characterization of $293 \mathrm{~T}$ cell-derived exosomes by profiling the protein, mRNA and MicroRNA components. PLoS One. 2016;11(9):e0163043.

20. Hong BS, Cho JH, Kim H, Choi EJ, Rho S, Kim J, et al. Colorectal cancer cell-derived microvesicles are enriched in cell cycle-related mRNAs that promote proliferation of endothelial cells. BMC Genomics. 2009:10:556.

21. Jenjaroenpun P, Kremenska Y, Nair VM, Kremenskoy M, Joseph B, Kurochkin IV. Characterization of RNA in exosomes secreted by human breast cancer cell lines using next-generation sequencing. PeerJ. 2013;1:e201.

22. Lazaro-Ibanez E, Lunavat TR, Jang SC, Escobedo-Lucea C, Oliver-De La Cruz J, Siljander P, et al. Distinct prostate cancer-related mRNA cargo in extracellular vesicle subsets from prostate cell lines. BMC Cancer. 2017;17(1):92.

23. Valadi H, Ekstrom K, Bossios A, Sjostrand M, Lee JJ, Lotvall JO. Exosomemediated transfer of mRNAs and microRNAs is a novel mechanism of genetic exchange between cells. Nat Cell Biol. 2007;9(6):654-9.

24. Yeo-Teh NSL, Ito Y, Jha S. High-risk human papillomaviral oncogenes E6 and E7 target key cellular pathways to achieve oncogenesis. Int J Mol Sci. 2018;19(6):1706.

25. Richard C, Lanner C, Naryzhny SN, Sherman L, Lee H, Lambert PF, et al. The immortalizing and transforming ability of two common human papillomavirus 16 E6 variants with different prevalences in cervical cancer. Oncogene. 2010:29(23):3435-45.

26. Honegger A, Leitz J, Bulkescher J, Hoppe-Seyler K, Hoppe-Seyler F. Silencing of human papillomavirus (HPV) E6/E7 oncogene expression affects both the contents and the amounts of extracellular microvesicles released from HPV-positive cancer cells. Int J Cancer. 2013;133(7):1631-42. 
27. Honegger A, Schilling D, Bastian S, Sponagel J, Kuryshev V, Sultmann $\mathrm{H}$, et al. Dependence of intracellular and exosomal microRNAs on viral E6/E7 oncogene expression in HPV-positive tumor cells. PLoS Pathog. 2015;11(3):e1004712.

28. Chiantore MV, Mangino G, Iuliano M, Zangrillo MS, De Lillis I, Vaccari G, et al. Human papillomavirus E6 and E7 oncoproteins affect the expression of cancer-related microRNAs: additional evidence in HPV-induced tumorigenesis. J Cancer Res Clin Oncol. 2016;142(8):1751-63.

29. Bhat A, Sharma A, Bharti AC. Upstream Hedgehog signaling components are exported in exosomes of cervical cancer cell lines. Nanomedicine. 2018;13(17):2127-38.

30. Wu Y, Deng W, Klinke DJ 2nd. Exosomes: improved methods to characterize their morphology, RNA content, and surface protein biomarkers. Analyst. 2015;140(19):6631-42.

31. Thery C, Amigorena S, Raposo G, Clayton A. Isolation and characterization of exosomes from cell culture supernatants and biological fluids. Curr Protoc Cell Biol. 2006; Chapter 3:Unit 322.

32. Vishnoi K, Mahata S, Tyagi A, Pandey A, Verma G, Jadli M, et al. Cross-talk between human papillomavirus oncoproteins and hedgehog signaling synergistically promotes stemness in cervical cancer cells. Sci Rep. 2016;6:34377.

33. Ewels $P$, Magnusson M, Lundin S, Kaller M. MultiQC: summarize analysis results for multiple tools and samples in a single report. Bioinformatics. 2016;32(19):3047-8.

34. Chen S, Zhou Y, Chen Y, Gu J. fastp: an ultra-fast all-in-one FASTQ preprocessor. Bioinformatics. 2018;34(17):i884-90.

35. Dobin A, Davis CA, Schlesinger F, Drenkow J, Zaleski C, Jha S, et al. STAR ultrafast universal RNA-seq aligner. Bioinformatics. 2013;29(1):15-21.

36. Pertea M, Pertea GM, Antonescu CM, Chang TC, Mendell JT, Salzberg SL. StringTie enables improved reconstruction of a transcriptome from RNAseq reads. Nat Biotechnol. 2015;33(3):290-5.

37. Pertea G, Pertea M: GFF utilities: GffRead and GffCompare. F1000Research 2020;9:ISCB Comm J-304.

38. Love MI, Huber W, Anders S. Moderated estimation of fold change and dispersion for RNA-seq data with DESeq2. Genome Biol. 2014;15(12):550.

39. Yu G, Wang LG, Han Y, He QY. clusterProfiler: an R package for comparing biological themes among gene clusters. Omics. 2012;16(5):284-7.

40. Kanehisa M, Furumichi M, Sato Y, Ishiguro-Watanabe M, Tanabe M. KEGG: integrating viruses and cellular organisms. Nucleic Acids Res. 2021;49(D1):D545-51.

41. Walter W, Sanchez-Cabo F, Ricote M. GOplot: an R package for visually combining expression data with functional analysis. Bioinformatics. 2015;31(17):2912-4.

42. Luo W, Brouwer C. Pathview: an R/Bioconductor package for pathway-based data integration and visualization. Bioinformatics. 2013;29(14):1830-1.

43. Verweij FJ, Bebelman MP, Jimenez CR, Garcia-Vallejo JJ, Janssen H, Neefjes $J$, et al. Quantifying exosome secretion from single cells reveals a modulatory role for GPCR signaling. J Cell Biol. 2018;217(3):1129-42.

44. Ravasi T, Suzuki H, Pang KC, Katayama S, Furuno M, Okunishi R, et al. Experimental validation of the regulated expression of large numbers of non-coding RNAs from the mouse genome. Genome Res. 2006;16(1):11-9.

45. Batagov AO, Kurochkin IV. Exosomes secreted by human cells transport largely mRNA fragments that are enriched in the 3 '-untranslated regions. Biol Direct. 2013;8:12.

46. Wei Z, Batagov AO, Schinelli S, Wang J, Wang Y, El Fatimy R, et al. Coding and noncoding landscape of extracellular RNA released by human glioma stem cells. Nat Commun. 2017;8(1):1145.

47. Wright AA, Howitt BE, Myers AP, Dahlberg SE, Palescandolo E, Van Hummelen $P$, et al. Oncogenic mutations in cervical cancer: genomic differences between adenocarcinomas and squamous cell carcinomas of the cervix. Cancer. 2013;119(21):3776-83.

48. Madeo M, Colbert PL, Vermeer DW, Lucido CT, Cain JT, Vichaya EG, et al. Cancer exosomes induce tumor innervation. Nat Commun. 2018;9(1):4284.

49. Lucido CT, Wynja E, Madeo M, Williamson CS, Schwartz LE, Imblum BA, et al. Innervation of cervical carcinoma is mediated by cancer-derived exosomes. Gynecol Oncol. 2019;154(1):228-35.

50. Blair HJ, Tompson S, Liu YN, Campbell J, MacArthur K, Ponting CP, et al. Evc2 is a positive modulator of Hedgehog signalling that interacts with
Evc at the cilia membrane and is also found in the nucleus. BMC Biol. 2011;9:14.

51. Zeng K, He B, Yang BB, Xu T, Chen X, Xu M, et al. The pro-metastasis effect of circANKS1B in breast cancer. Mol Cancer. 2018;17(1):160.

52. Urbanelli L, Buratta S, Tancini B, Sagini K, Delo F, Porcellati S, et al. The Role of Extracellular Vesicles in Viral Infection and Transmission. Vaccines. 2019;7(3):102.

53. Herberich SE, Klose R, Moll I, Yang WJ, Wustehube-Lausch J, Fischer A. ANKS1B interacts with the Cerebral cavernous malformation protein-1 and controls endothelial permeability but not sprouting angiogenesis. PLoS One. 2015;10(12):e0145304.

54. Goncalves J, Sharma A, Coyaud E, Laurent EMN, Raught B, Pelletier L. LUZP1 and the tumor suppressor EPLIN modulate actin stability to restrict primary cilia formation. J Cell Biol. 2020;219(7):e201908132.

55. Samuel P, Mulcahy LA, Furlong F, McCarthy HO, Brooks SA, Fabbri M, et al. Cisplatin induces the release of extracellular vesicles from ovarian cancer cells that can induce invasiveness and drug resistance in bystander cells. Philos Trans R Soc Lond Ser B Biol Sci. 2018;373(1737):20170065.

56. Nemeth A, Orgovan N, Sodar BW, Osteikoetxea X, Paloczi K, SzaboTaylor KE, et al. Antibiotic-induced release of small extracellular vesicles (exosomes) with surface-associated DNA. Sci Rep. 2017;7(1):8202.

57. Toots M, Mannik A, Kivi G, Ustav M Jr, Ustav E, Ustav M. The transcription map of human papillomavirus type 18 during genome replication in U2OS cells. PLoS One. 2014;9(12):e116151.

58. Chen J, Xue Y, Poidinger M, Lim T, Chew SH, Pang CL, et al. Mapping of HPV transcripts in four human cervical lesions using RNAseq suggests quantitative rearrangements during carcinogenic progression. Virology. 2014;462-463:14-24.

59. Olmedo-Nieva L, Munoz-Bello JO, Contreras-Paredes A, Lizano M. The role of E6 spliced isoforms (E6*) in human papillomavirus-induced carcinogenesis. Viruses. 2018;10(1):45.

60. Tang S, Tao M, McCoy JP Jr, Zheng ZM. The E7 oncoprotein is translated from spliced E6*I transcripts in high-risk human papillomavirus type 16or type 18-positive cervical cancer cell lines via translation reinitiation. J virol. 2006;80(9):4249-63.

\section{Publisher's Note}

Springer Nature remains neutral with regard to jurisdictional claims in published maps and institutional affiliations.

Ready to submit your research? Choose BMC and benefit from:

- fast, convenient online submission

- thorough peer review by experienced researchers in your field

- rapid publication on acceptance

- support for research data, including large and complex data types

- gold Open Access which fosters wider collaboration and increased citations

- maximum visibility for your research: over $100 \mathrm{M}$ website views per year

At BMC, research is always in progress.

Learn more biomedcentral.com/submissions 